\title{
Improving the Mechanical Properties of Graphene Oxide Based Materials by
}

\section{Covalent Attachment of Polymer Chains}

Manuela Cano ${ }^{1}$, Umar Khan ${ }^{2,3}$, Toby Sainsbury ${ }^{2,3}$, Arlene O'Neill $^{2,3}$, Zhiming Wang ${ }^{3}$, Ignatius McGovern ${ }^{3}$, Wolfgang K Maser ${ }^{1 *}$, Ana M Benito ${ }^{1}$ and Jonathan N Coleman ${ }^{2,3}$

${ }^{1}$ Instituto de Carboquimica ICB-CSIC, C/Miguel Luesma Castán 4. E-50018 Zaragoza, Spain

${ }^{2}$ Centre for Research on Adaptive Nanostructures and Nanodevices (CRANN) \& School of Physics Trinity College Dublin, Dublin 2, Ireland.

${ }^{3}$ School of Physics, Trinity College Dublin, Dublin 2, Ireland.

\begin{abstract}
We report on the modification of graphene oxide (GO) with polyvinylalcohol (PVA) leading to the mechanical improvement of GO based materials. First, GO was covalently functionalised with PVA by esterification of carboxylic groups on GO with hydroxyl groups of PVA resulting in functionalised f-(PVA)GO. This was carried out for PVA of six different molecular weights. This functionalised graphene oxide could be formed into a paper-like material by vacuum filtration. Papers prepared from f-(PVA)GO showed significant increases in mechanical properties compared to those prepared with GO or with simple mixtures of GO and PVA. The best performance was achieved for PVA functional groups with molecular weights between 50 and $150 \mathrm{~kg} / \mathrm{mol}$. Improvements in Young's moduli of $60 \%$ and tensile strength of $400 \%$ were observed relative to GO-only paper. The improved mechanical properties are attributed to enhanced inter-flake stress transfer due to the covalently bonded PVA. Second, functionalised f-(PVA)GO was used as filler in
\end{abstract}

\footnotetext{
* Corresponding author. Tel/Fax: +34 976 73-3977 / -3318. E-mail address: wmaser@icb.csic.es (W.K. Maser)
} 
PVA-based composites. The application of a pre-selection method allowed the use of only the largest functionalised f-(PVA)GO flakes. This resulted in substantially reinforced PVA-f-(PVA)GO composites. Both modulus and strength increased by $40 \%$ relative to the pure polymer for $\mathrm{f}$ (PVA)GO loadings below 0.3 vol. $\%$.

\section{INTRODUCTION}

Graphene has generated intense excitement in recent years due to its remarkable properties [1, 2]. Of particular interest to materials scientists is the fact that graphene is the strongest and stiffest material known to man [3]. This immediately suggests that graphene sheets would be an ideal reinforcing agent for polymer composites as the reinforcement potential scales linearly with filler stiffness and strength [4]. In fact much work has already been done [5-7] showing that graphene and graphene oxide (GO) [8,9] are potentially effective reinforcements [10-19]. However, it has also been shown that the fracture of polymer-graphene composites is associated with failure of the polymer graphene interface [19]. Such failure occurs when the graphene flake length is shorter than the critical length $[4,20]$. While this obviously means the flakes are smaller than would be ideal, it also means that the polymer graphene interfacial strength is lower than would be desirable. This is unfortunate, as once the flake length is below the critical length, the rate of increase of strength with graphene volume fraction is limited by the interfacial strength [19]. This suggests that interfacial engineering is an important route to improve the properties of graphene composites.

It is likely that both the stress transfer from polymer to graphene and the interfacial strength could be improved by functionalising graphene with polymer chains. So long as they are chemically similar, the grafted polymer chains will mix easily with the polymer matrix resulting in an improved interface. Chemically, such functionalisation is easier to achieve with graphene oxide that graphene as carboxylic acid groups present are good potential targets for chemical modification. To this end, 
a number of groups have described covalent functionalisation of GO with polymer chains [21-27] .In some cases, this modification has resulted in very good reinforcement of polymers $[23,25,26$, 28, 29]. However, significant increases in strength at low filler content have not really been observed. The exception was one paper which reported increases in strength from $\sigma_{\mathrm{B}}=37 \mathrm{MPa}$ to $\sigma_{\mathrm{B}}=63 \mathrm{MPa}$ for a volume fraction of $\mathrm{V}_{\mathrm{f}} \approx 0.05 \%$. This is equivalent to $d \sigma_{\mathrm{B}} / \mathrm{dV}_{\mathrm{f}} \approx 55 \mathrm{GPa}$, a significant fraction of the theoretical value of $130 \mathrm{GPa}[3,4,19]$.

We believe that it is worthwhile exploring polymer functionalisation of GO with the aim of improving the mechanical properties of GO based materials. For example, in composites compatibility with the polymer matrix, and interfacial stress transfer would be improved by functionalisation. We suggest that polyvinyl alcohol (PVA) is a good model polymer for this work as it is commonly used as a model matrix for nano-composite studies [30-32]. In this paper we first describe the functionalisation of graphene oxide with polyvinyl alcohol to give f-(PVA)GO. The functionalised graphene can be used to fabricate paper-like materials. We observe significant increase of mechanical properties of f-(PVA)GO papers compared to those prepared with GO or with simple mixtures of GO and PVA. Second, we describe the use of the functionalised f(PVO)GO as a filler material to prepare composites of f-(PVA)GO in PVA. These composites were significantly stiffer and stronger than the pristine polymer.

\section{EXPERIMENTAL PROCEDURE}

2.1 Graphite oxide synthesis

Preparation of graphite oxide was carried out using a slightly modified Hummers method; graphite powder was oxidized using $\mathrm{NaNO}_{3}, \mathrm{H}_{2} \mathrm{SO}_{4}$ and $\mathrm{KMNO}_{4}$ in an ice bath [33]. The material obtained was centrifuged at $2000 \mathrm{rpm}$ for 10 minutes. The supernatant, containing inorganic salts 
was decanted, and the deposit washed several times with deionized water until the $\mathrm{pH}$ was neutral. This sediment was dried overnight in a vacuum oven at $80^{\circ} \mathrm{C}$.

2.2 Exfoliation of graphite oxide and functionalisation

Graphene oxide, GO, was covalently attached to polyvinyl alcohol by a carbodiimide esterification reaction (see Figure 1) [34] following the experimental conditions of Salavagione et. al. with some modifications [27]. In a typical reaction, the graphite oxide (50 $\mathrm{mg})$ was dispersed in $10 \mathrm{ml}$ of dimethyl sulfoxide (DMSO) and sonicated for 24 hours in order to effectively exfoliate and disperse the graphite oxide. Next, N,N-dicyclohexylcarbodiimide (DCC) (100 mg, $0.48 \mathrm{mmol}$ ) and 4-dimethylaminopyridine (DMAP) (5 mg, $0.04 \mathrm{mmol})$ were added and the resulting mixture bath-sonicated for 4 hours.

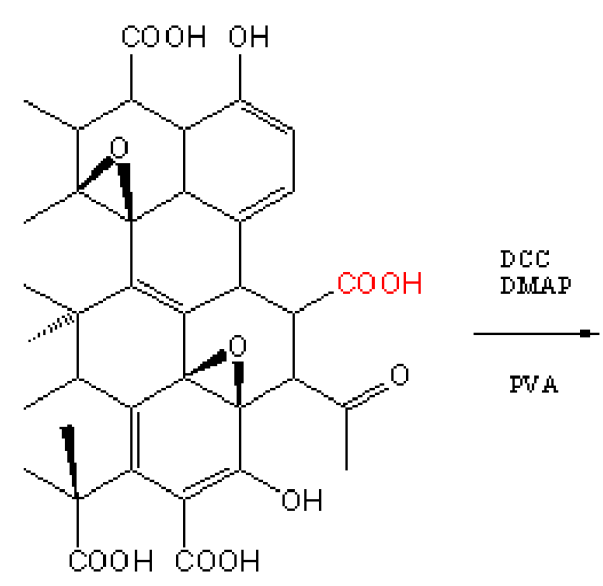

$\mathrm{R}-\mathrm{COOH}$

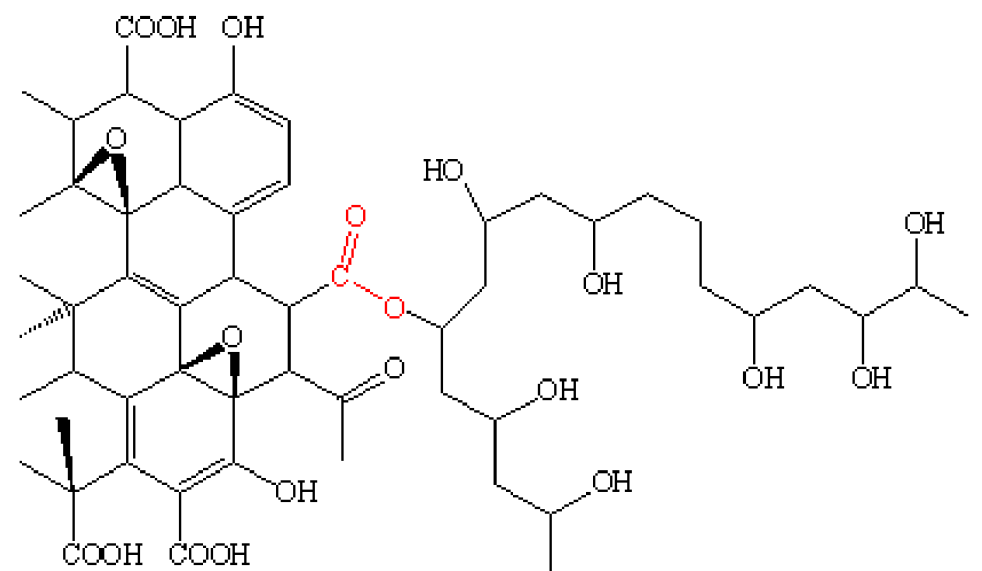

$\mathrm{R}-\mathrm{COO}-\mathrm{R}$

Figure 1. Functionalisation of graphene oxide with polyvinylalcohol by a carbodiimide esterification reaction.

Polyvinyl alcohol was then covalently attached to the GO. This was carried for six different molecular weights between 6 to $500 \mathrm{~kg} / \mathrm{mol}$. For each molecular weight, a solution of polyvinyl alcohol (50 mg) in DMSO (10ml) was prepared and bath-sonicated until complete dissolution (30 to 
120 min, depending on the molecular weight of PVA). Subsequently, both solutions were mixed, and the mixture bath-sonicated at room temperature for 2 days. The functionalised GO was precipitated by adding $40 \mathrm{ml}$ of acetone to the mixture and the resulting solid filtered through a nylon membrane $(0.45 \mu \mathrm{m})$, and washed with water $(2 \mathrm{~L})$ in order to remove excess of PVA. The resulting functionalised $\mathrm{GO}$ material is referred to as $\mathrm{f}-(\mathrm{PVA}) \mathrm{GO}$.

\subsection{Paper-like materials preparation}

Paper-like materials of GO, and of the six functionalised f-(PVA)GO materials were prepared as follows. In a typical procedure, $50 \mathrm{mg}$ of the solid material were suspended in distilled water $(500 \mathrm{~mL})$, and the suspension bath-sonicated for 24 hours in order to obtain an aggregate-free dispersion. This low concentration dispersion was centrifuged at $500 \mathrm{rpm}$ for 45 minutes to remove the largest aggregates, and the supernatant separated from the sediment. The supernatant was slowly filtered through a $0.45 \mu \mathrm{m}$ polyester membrane, and the resulting paper-like material, peeled-off from the membrane, was dried at room temperature for 24 hours, followed by further thermal treatment at $60{ }^{\circ} \mathrm{C}$ during 24 hours. GO and f-(PVA)GO paper like materials, with an average thickness of $13 \mu \mathrm{m}$ and $30 \mu \mathrm{m}$, respectively, were cut into $2.25 \mathrm{~mm}$ width strips for tensile testing measurements. In this way, six different f-(PVA)GO paper materials, using grafted PVA of different molecular weights $(6,18,50,78,145$, and $500 \mathrm{~kg} / \mathrm{mol})$, were prepared. Additionally, paper-like materials from mixtures of non-functionalised GO and PVA, using PVA of two molecular weights $(6$, and $50 \mathrm{~kg} / \mathrm{mol})$ were fabricated under the same conditions.

2.4 PVA based composite preparation using functionalised $\mathrm{f}$-(PVA)GO as filler

The functionalised f-(PVA)GO material obtained in the previous section was also used to prepare corresponding PVA-f-(PVA)GO composites. For these studies, the functionalised material with PVA of $50 \mathrm{~kg} / \mathrm{mol}$ was used. With the purpose of maximizing reinforcement, a protocol of 
several centrifugation steps was followed in order to separate the larger-sized functionalised f(PVA)GO sheets from the smaller ones [19]. To achieve this, a suspension of f-(PVA)GO in distilled water $\left(0.6 \mathrm{mg} \mathrm{mL}^{-1}\right)$ was prepared by 2 hours bath-sonication. The obtained dispersion was left at room temperature overnight and then centrifuged at $500 \mathrm{rpm}$ for 45 minutes remove any large graphitic material. The supernatant was separated and centrifuged at $1000 \mathrm{rpm}$ for 45 minutes. In this scenario, the smaller f-(PVA)GO flakes would remain dispersed while the larger flakes would be found in the sediment [35]. This sediment, containing large flakes, and therefore more suitable to maximize reinforcement [19], has been used to prepare composites of f-(PVA)GO in a PVA matrix. A given amount of the sediment was added to a $5 \mathrm{mg} \cdot \mathrm{ml}^{-1}$ PVA solution to prepare a set of composites at low mass fraction. For the matrix PVA, a molecular weight of $78 \mathrm{~kg} / \mathrm{mol}$ was used, largely to facilitate comparison with other previously published data [19]. Additionally, to study the effect of flake size, composites were prepared using non-centrifuged supernatant f-(PVA)GO which contained both larger and smaller flakes. In all cases, the resulting dispersions had a constant mass of $60 \mathrm{mg}$ (together polymer and filler). The dispersions were bath-sonicated for 4 hours, drop-casted into $1 \mathrm{~cm} \times 2 \mathrm{~cm} \times 2 \mathrm{~cm}$ Teflon trays and dried in a vacuum oven, first at $40^{\circ} \mathrm{C}$ until total evaporation of the solvent and afterwards at $80^{\circ} \mathrm{C}$ for 1 day. The drop-casted films obtained were $\sim 27 \mu \mathrm{m}$ thick, and were cut into strips of $2.25 \mathrm{~mm}$ width. The mass fraction was converted to volume fraction assuming the densities of PVA and f-(PVA)GO to be 1300 and $2200 \mathrm{~kg} / \mathrm{m}^{3}$ respectively. This resulted in a set of films with volume fractions of $0,0.05,0.1,0.24$, and 0.36 vol\% f-(PVA)GO.

\subsection{Characterization}

X-ray photoelectron spectroscopy (XPS) was performed on vacuum filtered films in a system equipped with a VG CLAM II electron analyzer and PSP twin anode source. Mg Ka $(\mathrm{h} v=1253.6 \mathrm{eV})$ spectra were recorded at $10 \mathrm{eV}$ pass energy and $2 \mathrm{~mm}$ slits, yielding an overall 
energy resolution of $0.85 \mathrm{eV}$. Samples were introduced via a loadlock and measurement base pressure was better than $10^{-9}$ mbar. TEM samples were prepared by pipetting $5 \mu \mathrm{L}$ of a dispersion in water onto holey carbon mesh grids (400 mesh) and allowing the solvent to evaporate under ambient conditions. Bright-field TEM images were taken with a Jeol 2100, operated at $200 \mathrm{kV}$.

Infrared spectra $\left(4000-500 \mathrm{~cm}^{-1}\right)$ were recorded on a Perkin-Elmer Spectrum One spectrophotometer. SEM analysis was carried out in a Hitachi S-4300 field emission SEM. Mechanical testing was performed using a Zwick Roell tensile tester with $100 \mathrm{~N}$ load cell at a strain rate of $0.5 \mathrm{~mm} / \mathrm{mmin}$ and $5 \mathrm{~mm} / \mathrm{min}$ for paper-like materials, and PVA composites respectively. Under these conditions, five stripes of each material were tested.

\section{RESULTS AND DISCUSSION}

\subsection{Functionalised f-(PVA)GO materials}

We initially characterized the functionalised GO material by transmission electron microscopy. Shown in figure 2A-C are TEM images of a typical sample after the smaller flakes have been removed by centrifugation (see below). While the initially prepared flakes had lateral sizes from a few hundred nanometers to a few microns, those in figure 2 have lengths between 1 and 7 microns. 

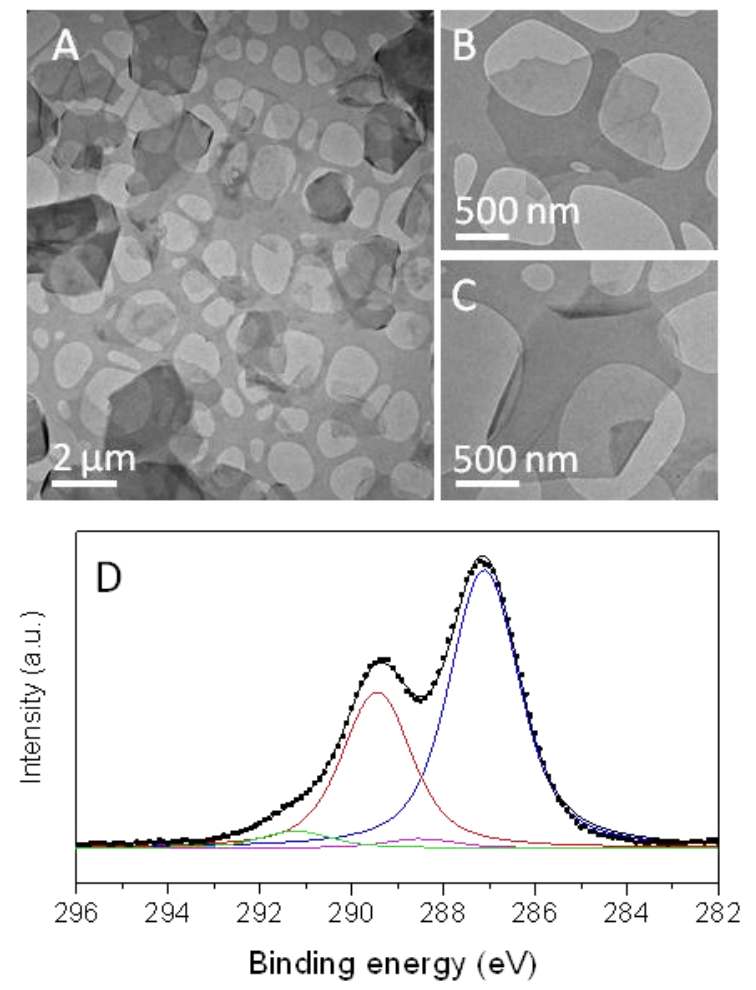

Figure 2. A-C) TEM images of graphene oxide flakes prepared during this work. Note, these images are of size selected flakes i.e. the smaller flakes have been removed. D) C1s X-ray photoelectron spectrum of the GO produced in this work. The experimental curve has been fit to four peaks after the Shirley background has been subtracted. Note that the spectrum has a global binding energy shift of $2.2 \mathrm{eV}$ due to charging

An analysis of the surface composition of the graphite oxide by XPS (Fig. 2D) showed a considerable degree of oxidation with several carbonaceous features related to carbon bonded to oxygen. In detail, the C1s XPS spectrum exhibited four features, at positions of $287 \mathrm{eV}, 288.5 \mathrm{eV}$, $289.5 \mathrm{eV}$ and $291.3 \mathrm{eV}$ in the proportions $61 \%, 2 \%, 34 \%$ and $3 \%$, respectively. Previous analysis [9, 36-41] of GO using XPS has shown a number of groups with the mean observed position given in brackets: C-C (284.8 eV), C-OH (286.3 eV), C-O-C (287.0 eV), C=O $(287.8 \mathrm{eV})$ and $\mathrm{C}(\mathrm{O}) \mathrm{O}$ (289.4 eV). It is likely that the peak observed by us at $287 \mathrm{eV}$ represents $\mathrm{C}-\mathrm{C}$ but is shifted by 2.2 $\mathrm{eV}$ due to charging. With this in mind, we identify the peaks observed in this work along with their associated fractional contribution as $\mathrm{C}-\mathrm{C}(287 \mathrm{eV}, 61 \%)$, either $\mathrm{C}-\mathrm{O}-\mathrm{C}$ or $\mathrm{C}=\mathrm{O}(289.5 \mathrm{eV}, 34 \%)$, 
$\mathrm{C}(\mathrm{O}) \mathrm{O}(291.3 \mathrm{eV}, 3 \%)$ and $\mathrm{C}-\mathrm{OH}(288.5 \mathrm{eV}, 2 \%)$. We note that while these results are broadly in line with previous reports $[9,36-41]$, some notable differences exist. Usually, relatively intense peaks for both $\mathrm{C}=\mathrm{O}$ and $\mathrm{C}-\mathrm{O}-\mathrm{C}$ are observed. Here only one peak is observed which we cannot definitively assign to either of these groups. Our work shows the $\mathrm{C}(\mathrm{O}) \mathrm{O}$ peak to be weak, in line with most reports and consistent with the expectations that this group should be limited to flake edges. In addition, as with our results, many reports show the $\mathrm{C}-\mathrm{OH}$ peak to be relatively weak. However, at least one publicationshows the $\mathrm{C}-\mathrm{OH}$ peak to almost as intense as the $\mathrm{C}-\mathrm{C}$ peak [37]. In any case, these results show the GO produced here to be relatively well oxidized in line with expectations.

FTIR analysis (Fig. 3) gave further evidence on the chemical oxidation of the graphite oxide surface, showing this spectrum the characteristic FTIR bands at 1570, 1715 and $3400 \mathrm{~cm}^{-1}$, that can be assigned to $\mathrm{C}=\mathrm{C}, \mathrm{C}=\mathrm{O}$ (carboxylic acid moieties) and $\mathrm{O}-\mathrm{H}$ stretching vibrations [42]. In the FTIR spectra of the neat PVA and functionalised f-(PVA)GO materials (Fig.3), the presence of an intense $\mathrm{O}-\mathrm{H}$ stretching absorption between 3000 and $3500 \mathrm{~cm}^{-1}$ indicated the existence of strong intermolecular and intramolecular hydrogen bonding. The higher intensity and larger width of this band in the f-(PVA)GO spectrum suggested that these interactions are significantly stronger in the functionalised material. The absorption at $1720 \mathrm{~cm}^{-1}$, corresponding to the stretching vibration of $\mathrm{C}=\mathrm{O}$ ester groups formed between the carboxylic acid groups of $\mathrm{GO}$ and the alcohol groups of PVA, appears with higher intensity in the f-(PVA)GO spectrum, indicating on one hand that PVA has indeed been covalently attached to the GO (scheme 1), and on the other that hydrogen bonding between $\mathrm{C}=\mathrm{O}$ and $\mathrm{OH}$ has been established, agreeing with the observed increase of the $\mathrm{OH}$ band. The band at around $1100 \mathrm{~cm}^{-1}$ in PVA, corresponding to C-O stretching increased in intensity, and down-shifted by $32 \mathrm{~cm}^{-1}$ in the $\mathrm{f}-(\mathrm{PVA}) \mathrm{GO}$ material. Also this band became wider because of the appearance of new absorptions between 950 and $915 \mathrm{~cm}^{-1}$. These were assigned to characteristic 
bands of the carboxylic group, not present in neat PVA. Based on the spectral results, it is reasonable to conclude on an effective functionalisation of the GO by PVA.

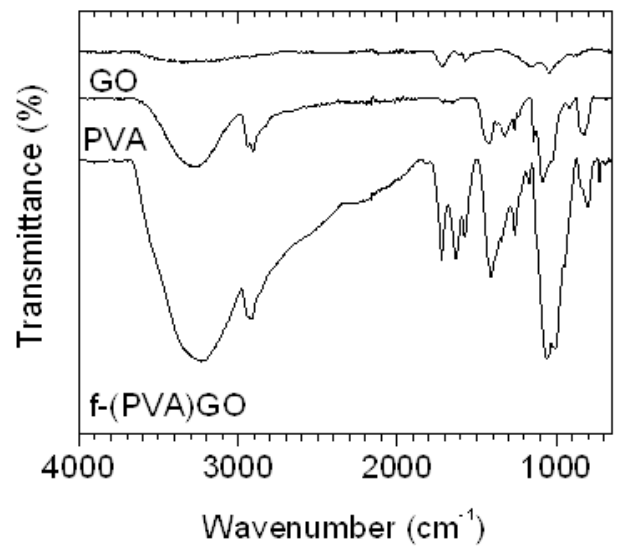

Figure 3. FTIR spectra of thin paper-like materials of GO, PVA, and f-(PVA)GO. The paper-like materials were produced by vacuum filtration. The spectra have been shifted vertically for sake of clarity.

3.2 Physical properties of paper-like materials

It is of interest to study the effect of functionalisation on the resulting properties of macroscopic materials. For this reason, we prepared paper-like materials from f-(PVA)GO (with PVA of 6 different molecular weights) and compared their mechanical properties with paper-like materials prepared from GO, and from mixtures of non-functionalised GO and PVA (with 2 different molecular weights, $6 \mathrm{~kg} / \mathrm{mol}$, and $50 \mathrm{~kg} / \mathrm{mol})$.

SEM analysis of the fracture surfaces of the GO paper-like material (Figure 4A) showed that GO paper consisted of GO flakes well-aligned in the plane of the paper as observed previously [43]. The majority of flakes appear to be above $1 \mu \mathrm{m}$ in lateral size. However, the f-(PVA)GO paper-like material looks distinctly different (Figure 4B shows the functionalised material with PVA of 145 
$\mathrm{kg} / \mathrm{mol}$ as an example). While the fracture surface also appears to be stratified, the flakes seemed much less well defined. This is exactly what it would be expected if they were covered with a polymer coating, and is consistent with the effective functionalisation achieved and proved by FTIR results previously discussed.
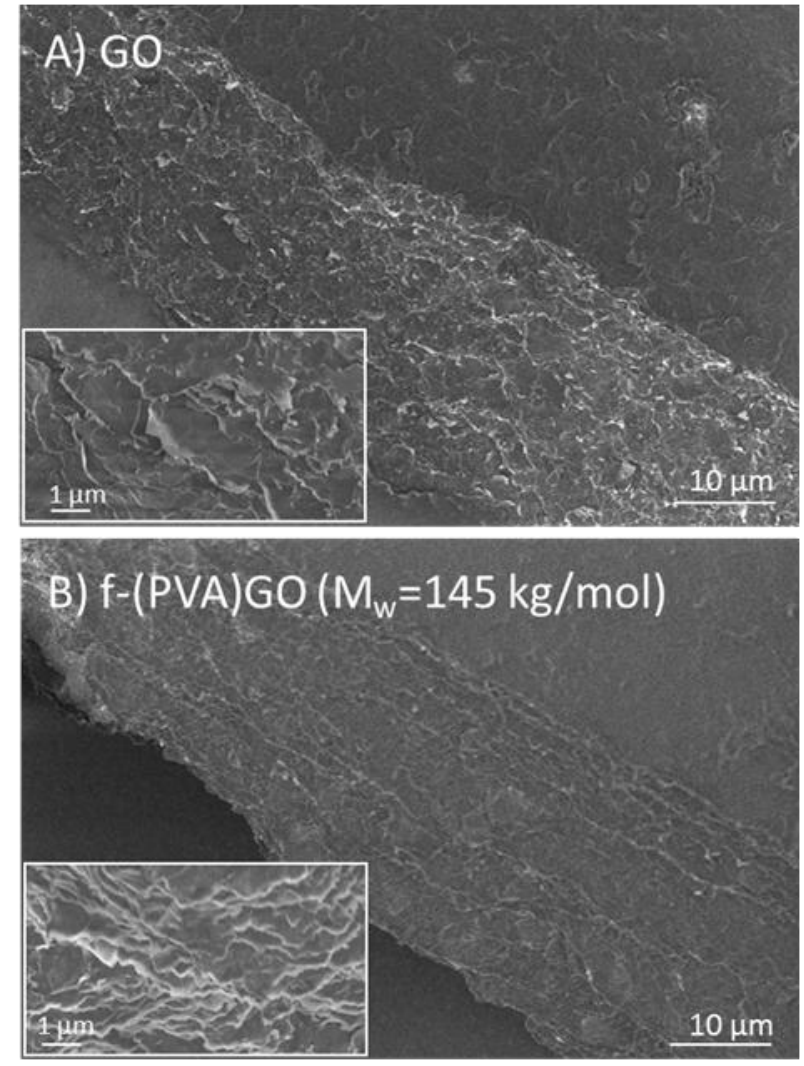

Figure 4. SEM images of fracture surfaces of vacuum filtered paper-like materials of A) GO and B) f-(PVA)GO.

Effective functionalisation and formation of a thin PVA layer around GO in f-(PVA)GO drastically impacts on the mechanical properties of the corresponding papers. Representative stress strain curves for these samples are shown in Figure 5A. It can immediately be seen that the curves of f-(PVA)GO paper-like materials differed significantly from that of the GO paper. We can summarize this data by focusing on the Young's modulus, $Y$, the tensile strength, $\sigma_{\mathrm{B}}$, and the strain at break, $\varepsilon_{\mathrm{B}}$, as shown in figure 5B-D. It is clear from this data that a simple mixing of GO with PVA has a negative effect on the modulus of the obtained paper, and results in no change of the 
strength. In contrast, both, modulus and strength of the f-(PVA)GO paper-like material significantly increased in comparison with the GO paper. This is further evidence of the effective functionalisation of GO by PVA in the f-(PVA)GO papers. Otherwise, if the PVA and GO were only van der Waals bonded, one would expect to see mechanical performances similar to that of the simple GO and PVA mixtures. In contrast, the strain at break is similar for both, functionalised and mixed samples. In addition, $\varepsilon_{\mathrm{B}}$ increased on the introduction of the polymer. This indicates that while the presence of the polymer delays failure, the polymer does not need to be covalently bound to the GO. It may be that adsorbed polymer tends to form fibrils under strain connecting GO sheets and allowing the paper-like material to resist fracture to higher strains.
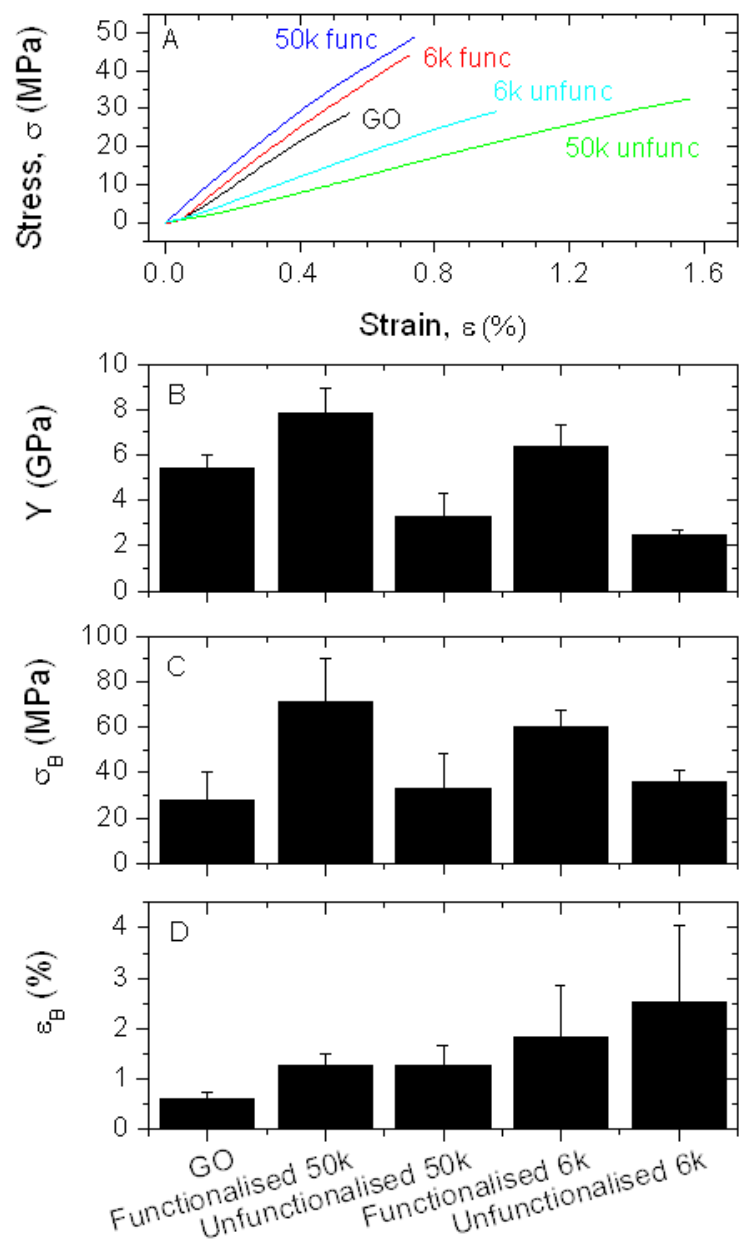

Figure 5. Comparison of mechanical properties of paper-like materials from GO, f-(PVA)GO (functionalised) and from simple mixtures of GO and PVA (non-functionalised). These 
measurements were made for PVA of two different molecular weights, $6 \mathrm{~kg} / \mathrm{mol}$ and $50 \mathrm{~kg} / \mathrm{mol}$. A) Representative stress strain curves. B) Young's modulus, C) ultimate tensile strength and C) strain at break.

The modulus and strength data described above suggested that covalent attachment of polymer chains to the GO increases both inter-flake stress transfer (as evidenced by the modulus increase) and inter-flake shear strength (as evidenced by the strength increase). It is of interest to consider the mechanism controlling this. It is likely that PVA chains of two adjacent f-(PVA)GO sheets, would interact with each other through entanglement. Indeed, since paper fabrication is carried out in liquid phase, enough solvent is present to provide the PVA chains sufficient mobility to facilitate this process. Entanglement should increase both inter-flake stress transfer and shear strength. The degree of increase would be expected to depend on the molecular weight of the grafted chains. Lower molecular weight means smaller radii of gyration of the polymer coils and so more chains per unit area of flake surface [44]. This should improve both stress transfer and shear strength. On the other hand, high molecular weight would mean a higher degree of entanglement [45], again potentially resulting in improved stress transfer and shear strength. The trade-off between these two competing factors suggests that an optimum molecular weight may exist where the modulus and strength show maxima.

To test this, we prepared f-(PVA)GO paper-like materials for a range of PVA molecular weights $(6 \mathrm{~kg} / \mathrm{mol}$ to $500 \mathrm{~kg} / \mathrm{mol})$. We measured the mechanical properties of these papers with representative stress strain curves shown in figure 6A. Plotted in figure 6B-D are the modulus, strength and strain at break values extracted from the stress strain curves. In each case, the red data point at $\mathrm{M}_{\mathrm{w}}=0$ represents GO. Although the modulus data was a little scattered, Y increased from $5 \mathrm{GPa}$ for GO to $\sim 8 \mathrm{GPa}$ for the $50 \mathrm{~kg} / \mathrm{mol}$ sample before falling off again. More dramatic changes 
were observed for the strength, which increased from $\sim 25 \mathrm{MPa}$ to $\sim 125 \mathrm{MPa}$ for the $150 \mathrm{~kg} / \mathrm{mol}$ sample before falling off for the $500 \mathrm{~kg} / \mathrm{mol}$ sample. These were much larger relative changes than found for GO paper which is cross linked by divalent ions for example [46]. Interestingly the strain at break also increased from $\sim 0.5 \%$ for the GO buckypaper to a peak value of $\sim 2 \%$ for the 150 $\mathrm{kg} / \mathrm{mol}$ sample before falling off to $\sim 1.5 \%$ for the $500 \mathrm{~kg} / \mathrm{mol}$ sample. This behaviour is probably not surprising, as the presence of entangled strands from adjacent flakes would certainly delay failure.
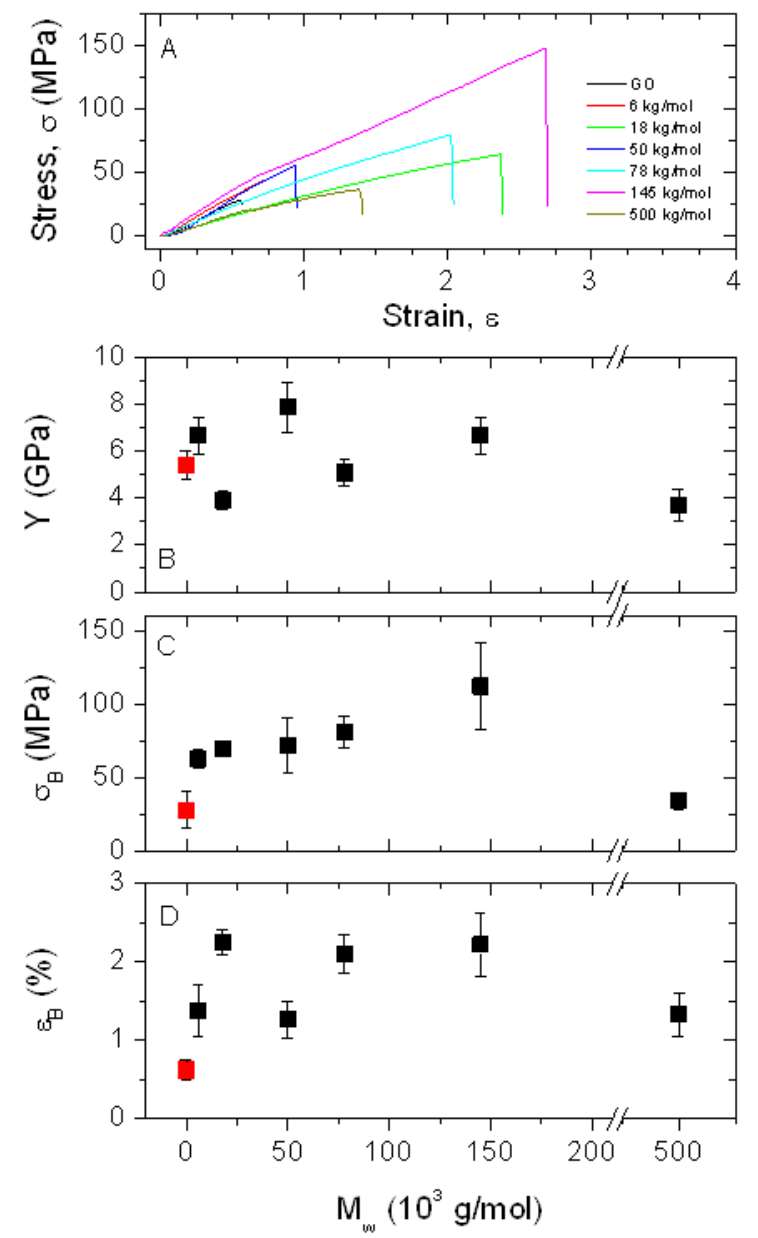

Figure 6. Mechanical properties of f-(PVA)GO paper-like materials as a function of the molecular weight of grafted PVA. A) Representative stress strain curves. B) Young's modulus, C) ultimate tensile strength and C) strain at break. 
3.3 PVA composites with f-(PVA)GO as filler material

Once it is known that the presence of covalently bonded PVA improves the inter-flake stress transfer and shear strength through processes such as chain entanglement, it becomes clear that interfacial stress transfer in polymer GO-PVA composites may be improved by the same mechanism. However, we note that flake size is very important for graphene-polymer composites with significant reinforcement only observed for large flakes [19, 47]. In fact, initially tests on composites of f-(PVA)GO in PVA using as-produced flakes showed no reinforcement. To address this, we used controlled centrifugation to remove smaller flakes and so increase the mean flake size [35]. We found that after size selection, the mean flake length and width were 3.0 and $1.7 \mu \mathrm{m}$ respectively.

We prepared composites of PVA filled with size selected flakes of both GO and f(PVA)GO. Representative tensile stress-strain curves for a subset of f-(PVA)GO in PVA composites are shown in figure 7A. It is clear from these curves that addition of $\mathrm{f}-(\mathrm{PVA}) \mathrm{GO}$ increased both modulus and strength of these composites. Similar curves for GO filled composites showed no reinforcements. Shown in figure 7B are data for composite Young's modulus as a function of f-(PVA)GO volume fraction. The modulus increased linearly from $2.5 \mathrm{GPa}$ for PVA to $\sim 4.5 \mathrm{GPa}$ for the $0.24 \mathrm{vol} \%$ sample beyond which the modulus falls off. The rate of increase in the linear regime is $\mathrm{dY} / \mathrm{dV}_{\mathrm{f}}=610 \pm 60 \mathrm{GPa}$. Similarly, the strength increased from $\sim 90 \mathrm{MPa}$ for PVA to $\sim 140 \mathrm{MPa}$ for the 0.24 vol\% sample before falling off. The slope of the linear region was $\mathrm{d} \sigma_{\mathrm{B}} / \mathrm{dV}_{\mathrm{f}}=22 \pm 2 \mathrm{GPa}$. We note that these were significant increases and are competitive with the best published results for polymers filled with either GO or pristine graphene [7, 10, 17, 19]. For comparison purposes, the data for the GO filled composites are also shown, illustrating the lack of 
reinforcement in this system. Shown in figure $7 \mathrm{C}$ is the strain at break as a function of filler content. Here the filler has no significant impact on the material ductility.
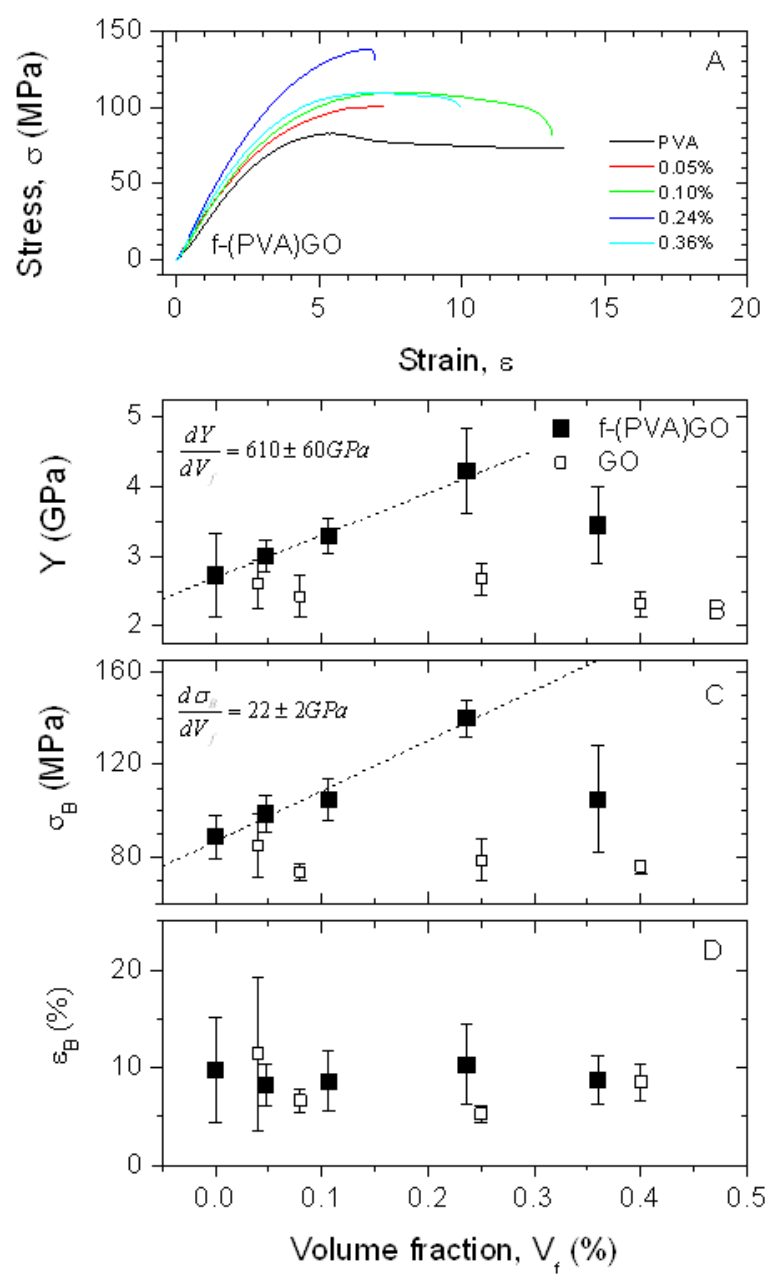

Figure 7. Mechanical properties of composites prepared from $\mathrm{f}-(\mathrm{PVA}) \mathrm{GO}\left(\mathrm{M}_{\mathrm{w}}=50 \mathrm{~kg} / \mathrm{mol}\right)$ dispersed in a PVA matrix $\left(\mathrm{M}_{\mathrm{w}}=78 \mathrm{~kg} / \mathrm{mol}\right.$. A) Representative stress strain curves. B) Young's modulus, C) ultimate tensile strength and C) strain at break.

We can put these results in perspective by comparison with the literature. We have performed a (non-exhaustive) survey of the literature for mechanical reinforcement of polymers using graphene and related materials $[10-19,23,25,26,28,29]$. We characterized the degree of reinforcement in two ways. Firstly, we considered the rate of increase in modulus and strength with 
filler volume fraction; $d Y / d V_{f}$ and $d \sigma_{B} / d V_{f}$. Obviously, good reinforcement is characterized by both of these parameters approaching their limiting values. These are determined by the mechanical properties of the filler; $d Y / d V_{f} \leq Y_{G}$ and $d \sigma_{B} / d V_{f} \leq \sigma_{G}$, where $Y_{G}$ and $\sigma_{G}$ are the graphene flake modulus and strength respectively $[4,19]$. The maximum values these parameters can reach are $\sim 1100 \mathrm{GPa}$ and $\sim 130 \mathrm{GPa}$, respectively for pristine graphene [3] with graphene oxide displaying somewhat lower values [48-50] Shown in figure 8A is published data for $\mathrm{dY} / \mathrm{dV}_{\mathrm{f}}$ plotted versus $\mathrm{d} \sigma_{\mathrm{B}} / \mathrm{dV}_{\mathrm{f}}$. It is clear that a large spread exists in the data. However, the results presented here are among the best reported.
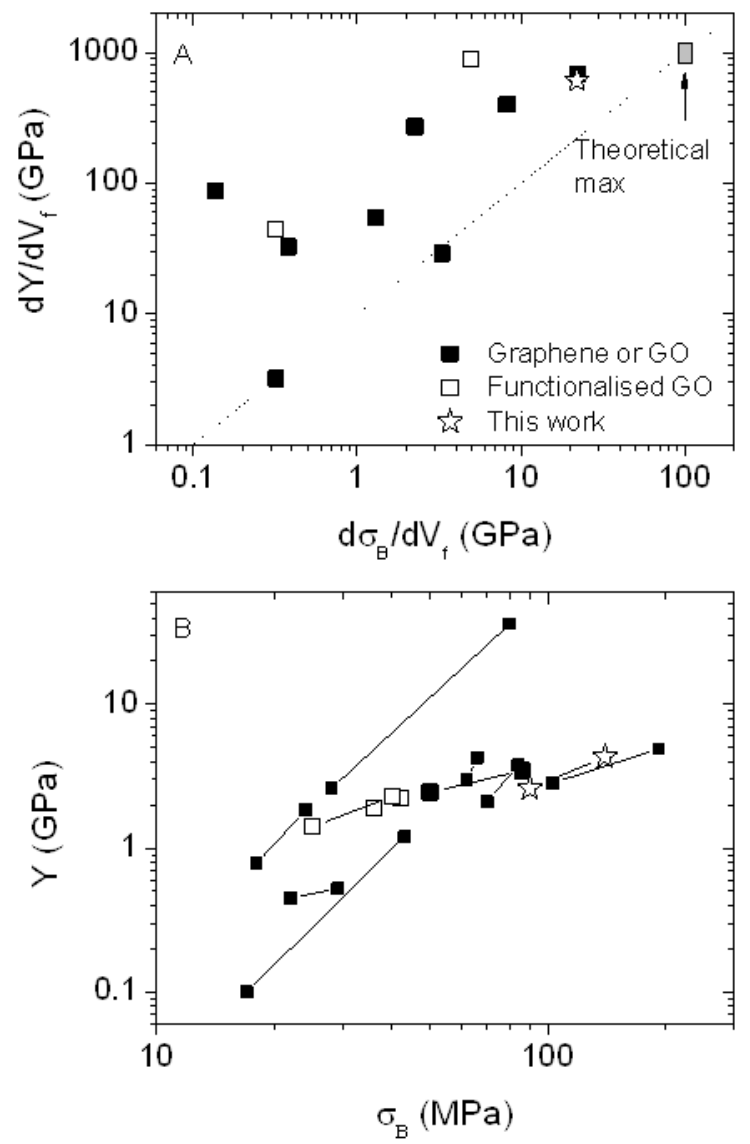

Figure 8. A) Data for $d Y / d V_{f}$ plotted as a function of $d \sigma_{\mathrm{B}} / \mathrm{dV}_{\mathrm{f}}$ for polymer/graphene composites from the literature. The data is differentiated between polymers filled with graphene or GO and polymers filled with polymer functionalised GO. The data from this paper are included for 
comparison. We have limited this graph to composites studied by tensile testing. In addition, in most cases, the rates of increase had to be estimated from the presented data. We assumed that polymer functionalised GO had a density similar to the matrix polymer. The theoretical maximum reinforcement is shown by the grey square. The dotted line represents ideal behaviour. B) Summery of increase in mechanical properties for graphene/polymer composites from the literature. The data consists of sets of two points joined by a line. In each case the lower data point represents the neat polymer. The upper data point represents the maximum reinforcement achieved. Note that one data set shows extremely good reinforcement. In this case the graphene volume fraction was $38 \%$ while for all other cases it was $<6 \%$. See table $\mathrm{S} 1$ for details of literature data.

For composites filled with aligned flakes with length above the critical length, the rate of increase in modulus and strength are given by $d Y / d V_{f} \approx \eta_{L Y} Y_{G}$ and $d \sigma_{B} / d V_{f} \approx \eta_{L \sigma} \sigma_{G}$. Here $\eta_{L Y}$ and $\eta_{L \sigma}$ are efficiency factors which scale with flake length and take values between 0 and 1 . Assuming that $\eta_{L Y}$ and $\eta_{L \sigma}$ have similar functional forms (true for the properties of typical graphene filled composites) [4], this means $d Y / d V_{f} \approx\left(Y_{G} / \sigma_{G}\right) d \sigma_{B} / d V_{f}$. It is known that $Y_{G} / \sigma_{G} \approx 10$ for graphene and graphene oxide, thus $d Y / d V_{f} \approx 10 d \sigma_{B} / d V_{f}$. This ideal behaviour has been plotted on figure $8 \mathrm{~A}$. It is clear from this plot that $d \sigma_{B} / d V_{f}$ is smaller than predicted for all composites. This is consistent with the graphene flakes being smaller than the critical value as observed previously [19]. This means that, for a given flake size, the composite strength is limited by the interfacial strength. While the GO-PVA composites described here are still to the left of the line, they are closer to the line than any other of the well performing materials. This illustrates that interfacial strength is reasonably good in these composites, validating the strategy to engineer the interface. 
We can also assess reinforcement via the increase in modulus and strength from polymer to best performing composite. This data is presented here as pairs of points joined by a line. The lower point represents the polymer while the upper point represents the composite. It is clear from this data that the reinforcement observed here is consistent with that achieved by other researchers. However, the properties of the best performing composite are among the best recorded, partly because the starting polymer has impressive mechanical properties.

\section{Conclusions}

In conclusion, we have demonstrated the effective functionalisation of graphene oxide sheets with polyvinyl alcohol. Functionalisation of GO with PVA allowed the preparation of vacuum filtered paper-like materials that were much stronger and stiffer than either those prepared from GO alone or simple mixtures of GO and PVA. We also found the mechanical properties of functionalised GO paper-like materials to depend strongly on the molecular weight of the attached polymer chains. The best performances are achieved for attached polymers with molecular weight between 50 and $150 \mathrm{~kg} / \mathrm{mol}$. Polymer functionalised GO flakes, f-(PVA)GO, were dispersed into polyvinylalcohol to form composites. Increases of approximate $60 \%$ in modulus and strength for f(PVA)GO loadings below 0.3 vol\% were achieved. This is among the best reinforcement observed for graphene based filler materials.

\section{Acknowledgements}

The authors would like to acknowledge Science Foundation Ireland, (grant number 07/IN.7/I1772), Spanish Ministry of Science and Innovation (MICINN) under project MAT2010-15026, Spanish Research Council CSIC under project 201080E124 and the Government of Aragon (DGA) under 
Project DGA-T66 CNN. M.C. thanks MICINN for her PhD contract and funding for research stay at TCD under FPI Programme BES-2008-003503.

\section{References}

[1] Geim AK. Graphene: Status and Prospects. Science. 2009;324(5934):1530-4.

[2] Geim AK, Novoselov KS. The rise of graphene. Nature Materials. 2007;6(3):183-91.

[3] Lee C, Wei X, Kysar JW, Hone J. Measurement of the Elastic Properties and Intrinsic Strength of Monolayer Graphene. Science. 2008;321(5887):385-8.

[4] Padawer GE, Beecher N. On the strength and stiffness of planar reinforced plastic resins. Polymer Engineering \& Science. 1970;10(3):185-92.

[5] Yang YG, Chen CM, Y.F. W, Yang QH, Wang MZ. Oxidized graphene and graphene based polymer composites. New Carbon Materials. 2008;23(3):193-200.

[6] Verdejo R, Bernal MM, Romasanta LJ, Lopez-Manchado MA. Graphene filled polymer nanocomposites. Journal of Materials Chemistry. 2011;21(10):3301-10.

[7] Kuilla T, Bhadra S, Yao D, Kim NH, Bose S, Lee JH. Recent advances in graphene based polymer composites. Progress in Polymer Science. 2010;35(11):1350-75.

[8] Stankovich S, Dikin DA, Dommett GHB, Kohlhaas KM, Zimney EJ, Stach EA, et al. Graphene-based composite materials. Nature. 2006;442(7100):282-6.

[9] Stankovich S, Dikin DA, Piner RD, Kohlhaas KA, Kleinhammes A, Jia Y, et al. Synthesis of graphene-based nanosheets via chemical reduction of exfoliated graphite oxide. Carbon. 2007;45(7):1558-65.

[10] Liang J, Huang Y, Zhang L, Wang Y, Ma Y, Guo T, et al. Molecular-Level Dispersion of Graphene into Poly(vinyl alcohol) and Effective Reinforcement of their Nanocomposites. Advanced Functional Materials. 2009;19(14):2297-302. 
[11] Putz KW, Compton OC, Palmeri MJ, Nguyen ST, Brinson LC. High-Nanofiller-Content Graphene Oxide-Polymer Nanocomposites via Vacuum-Assisted Self-Assembly. Advanced Functional Materials. 2010;20(19):3322-9.

[12] Miller SG, Bauer JL, Maryanski MJ, Heimann PJ, Barlow JP, Gosau J-M, et al. Characterization of epoxy functionalized graphite nanoparticles and the physical properties of epoxy matrix nanocomposites. Composites Science and Technology. 2010;70(7):1120-5.

[13] Jiang L, Shen X-P, Wu J-L, Shen K-C. Preparation and characterization of graphene/poly(vinyl alcohol) nanocomposites. Journal of Applied Polymer Science. 2010;118(1):275-9.

[14] Kim I-H, Jeong YG. Polylactide/exfoliated graphite nanocomposites with enhanced thermal stability, mechanical modulus, and electrical conductivity. Journal of Polymer Science Part B: Polymer Physics. 2010;48(8):850-8.

[15] Steurer P, Wissert R, Thomann R, Mülhaupt R. Functionalized Graphenes and Thermoplastic Nanocomposites Based upon Expanded Graphite Oxide. Macromolecular Rapid Communications. 2009;30(4-5):316-27.

[16] Zhao X, Zhang Q, Chen D, Lu P. Enhanced Mechanical Properties of Graphene-Based Poly(vinyl alcohol) Composites. Macromolecules. 2010;43(5):2357-63.

[17] Ramanathan T, Abdala AA, Stankovich S, Dikin DA, Herrera-Alonso M, Piner RD, et al. Functionalized graphene sheets for polymer nanocomposites. Nat Nanotechnol. 2008;3(6):327-31. [18] Yang X, Li L, Shang S, Tao X-M. Synthesis and characterization of layer-aligned poly(vinyl alcohol)/graphene nanocomposites. Polymer. 2010;51(15):3431-5.

[19] May P, Khan U, O'Neill A, Coleman JN. Approaching the theoretical limit for reinforcing polymers with graphene. Journal of Materials Chemistry. 2012;22(4):1278-82.

[20] Coleman JN, Khan U, Blau WJ, Gun'ko YK. Small but strong: A review of the mechanical properties of carbon nanotube-polymer composites. Carbon. 2006;44(9):1624-52. 
[21] Deng Y, Li Y, Dai J, Lang M, Huang X. An efficient way to functionalize graphene sheets with presynthesized polymer via ATNRC chemistry. Journal of Polymer Science Part A: Polymer Chemistry. 2011;49(7):1582-90.

[22] Veca LM, Lu F, Meziani MJ, Cao L, Zhang P, Qi G, et al. Polymer functionalisation and solubilization of carbon nanosheets. Chemical Communications. 2009(18):2565-7.

[23] Pramoda KP, Hussain H, Koh HM, Tan HR, He CB. Covalent Bonded Polymer-Graphene Nanocomposites. Journal of Polymer Science: Part A: Polymer Chemistry. 2010;48:4262-7.

[24] Kim H, Kobayashi S, AbdurRahim MA, Zhang MJ, Khusainova A, Hillmyer MA, et al. Graphene/polyethylene nanocomposites: Effect of polyethylene functionalization and blending methods. Polymer. 2011;52(8):1837-46.

[25] Gonçalves G, Marques PAAP, Barros-Timmons A, Bdkin I, Singh MK, Emami N, et al. Graphene oxide modified with PMMA via ATRP as a reinforcement filler. Journal of Materials Chemistry. 2010;20(44):9927-34.

[26] Fang M, Wang K, Lu H, Yang Y, Nutt S. Covalent polymer functionalization of graphene nanosheets and mechanical properties of composites. Journal of Materials Chemistry. 2009;19(38):7098-105.

[27] Salavagione HJ, Gómez MA, Martínez G. Polymeric Modification of Graphene through Esterification of Graphite Oxide and Poly(vinyl alcohol). Macromolecules. 2009;42(17):6331-4. [28] Prasad KE, Das B, Maitra U, Ramamurty U, Rao CNR. Extraordinary synergy in the mechanical properties of polymer matrix composites reinforced with 2 nanocarbons. Proceedings of the National Academy of Sciences. 2009;106(32):13186-9.

[29] Liu K, Chen L, Chen Y, Wu J, Zhang W, Chen F, et al. Preparation of polyester/reduced graphene oxide composites via in situ melt polycondensation and simultaneous thermo-reduction of graphene oxide. Journal of Materials Chemistry. 2011;21(24):8612-7. 
[30] Blighe FM, Young K, Vilatela JJ, Windle AH, Kinloch IA, Deng L, et al. The Effect of Nanotube Content and Orientation on the Mechanical Properties of Polymer-Nanotube Composite Fibers: Separating Intrinsic Reinforcement from Orientational Effects. Advanced Functional Materials. 2011;21(2):364-71.

[31] Coleman JN, Cadek M, Blake R, Nicolosi V, Ryan KP, Belton C, et al. High Performance Nanotube-Reinforced Plastics: Understanding the Mechanism of Strength Increase. Advanced Functional Materials. 2004;14(8):791-8.

[32] Young K, Blighe FM, Vilatela JJ, Windle AH, Kinloch IA, Deng L, et al. Strong Dependence of Mechanical Properties on Fiber Diameter for Polymer-Nanotube Composite Fibers: Differentiating Defect from Orientation Effects. ACS Nano. 2010 2010/11/23;4(11):6989-97.

[33] Hummers WS, Offeman RE. Preparation of Graphitic Oxide. Journal of the American Chemical Society. 1958;80(6):1339.

[34] Neises B, Steglich W. Simple Method for the Esterification of Carboxylic Acids. Angewandte Chemie International Edition in English. 1978;17(7):522-4.

[35] Khan U, O'Neill A, Porwal H, May P, Nawaz K, Coleman JN. Size selection of dispersed, exfoliated graphene flakes by controlled centrifugation. Carbon. 2012;50(2):470-5.

[36] Tang X-Z, Li W, Yu Z-Z, Rafiee MA, Rafiee J, Yavari F, et al. Enhanced thermal stability in graphene oxide covalently functionalized with 2-amino-4,6-didodecylamino-1,3,5-triazine. Carbon. 2011;49(4):1258-65.

[37] Jeong H-K, Noh H-J, Kim J-Y, Jin MH, Park CY, Lee YH. X-ray absorption spectroscopy of graphite oxide. Europhysics Letters. 2008;82(6):67004.

[38] Jeong HY, Kim JY, Kim JW, Hwang JO, Kim J-E, Lee JY, et al. Graphene Oxide Thin Films for Flexible Nonvolatile Memory Applications. Nano Letters. 2010 2010/11/10;10(11):43816. 
[39] Akhavan O. The effect of heat treatment on formation of graphene thin films from graphene oxide nanosheets. Carbon. 2010 Feb;48(2):509-19.

[40] Compton OC, Jain B, Dikin DA, Abouimrane A, Amine K, Nguyen ST. Chemically Active Reduced Graphene Oxide with Tunable C/O Ratios. Acs Nano. 2011 Jun;5(6):4380-91.

[41] Pei S, Zhao J, Du J, Ren W, Cheng H-M. Direct reduction of graphene oxide films into highly conductive and flexible graphene films by hydrohalic acids. Carbon. 2010;48(15):4466-74 .

[42] Marcano DC, Kosynkin DV, Berlin JM, Sinitskii A, Sun Z, Slesarev A, et al. Improved Synthesis of Graphene Oxide. ACS Nano. 2010;4(8):4806-14.

[43] Dikin DA, Stankovich S, Zimney EJ, Piner RD, Dommett GHB, Evmenenko G, et al. Preparation and characterization of graphene oxide paper. Nature. 2007;448(7152):457-60.

[44] Israelachvili JN. Intermolecular and Surface Forces. 2nd ed. New York: Academic Press 1991.

[45] Rubinstein M, Colby RH. Polymer Physics: Oxford University Press 2003.

[46] Park S, Lee KS, Bozoklu G, Cai W, Nguyen ST, Ruoff RS. Graphene oxide papers modified by divalent ions - Enhancing mechanical properties via chemical cross-linking. Acs Nano. 2008;2(3):572-8.

[47] Gong L, Kinloch IA, Young RJ, Riaz I, Jalil R, Novoselov KS. Interfacial Stress Transfer in a Graphene Monolayer Nanocomposite. Advanced Materials. 2010;22(24):2694-7.

[48] Gómez-Navarro C, Burghard M, Kern K. Elastic Properties of Chemically Derived Single Graphene Sheets. Nano Letters. 2008;8(7):2045-9.

[49] Paci JT, Belytschko T, Schatz GC. Computational Studies of the Structure, Behaviour upon Heating, and Mechanical Properties of Graphite Oxide. The Journal of Physical Chemistry C. 2007;111(49):18099-111.

[50] Suk JW, Piner RD, An J, Ruoff RS. Mechanical Properties of Monolayer Graphene Oxide. ACS Nano. 2010;4(11):6557-64. 


\section{Figure Captions}

Figure 1. Functionalisation of graphene oxide with polyvinylalcohol by a carbodiimide esterification reaction.

Figure 2. A-C) TEM images of graphene oxide flakes prepared during this work. Note, these images are of size selected flakes i.e. the smaller flakes have been removed. D) C1s X-ray photoelectron spectrum of the GO produced in this work. The experimental curve has been fit to four peaks after the Shirley background has been subtracted. Note that the spectrum has a global binding energy shift of $2.2 \mathrm{eV}$ due to charging.

Figure 3. FTIR spectra of thin paper-like materials of GO, PVA, and f-(PVA)GO. The paper-like materials were produced by vacuum filtration. The spectra have been shifted vertically for sake of clarity.

Figure 4. SEM images of fracture surfaces of vacuum filtered paper-like materials of A) GO and B) f-(PVA)GO.

Figure 5. Comparison of mechanical properties of paper-like materials from GO, f-(PVA)GO (functionalised) and from simple mixtures of GO and PVA (non-functionalised). These measurements were made for PVA of two different molecular weights, $6 \mathrm{~kg} / \mathrm{mol}$ and $50 \mathrm{~kg} / \mathrm{mol}$. A) Representative stress strain curves. B) Young's modulus, C) ultimate tensile strength and C) strain at break.

Figure 6. Mechanical properties of f-(PVA)GO paper-like materials as a function of the molecular weight of grafted PVA. A) Representative stress strain curves. B) Young's modulus, C) ultimate tensile strength and C) strain at break. 
Figure 7. Mechanical properties of composites prepared from f-(PVA)GO ( $\left.\mathrm{M}_{\mathrm{w}}=50 \mathrm{~kg} / \mathrm{mol}\right)$ dispersed in a PVA matrix $\left(\mathrm{M}_{\mathrm{w}}=78 \mathrm{~kg} / \mathrm{mol}\right.$. A) Representative stress strain curves. B) Young's modulus, C) ultimate tensile strength and C) strain at break.

Figure 8. A) Data for $d \mathrm{Y} / \mathrm{dV}_{\mathrm{f}}$ plotted as a function of $d \sigma_{\mathrm{B}} / \mathrm{dV}_{\mathrm{f}}$ for polymer/graphene composites from the literature. The data is differentiated between polymers filled with graphene or GO and polymers filled with polymer functionalised GO. The data from this paper are included for comparison. We have limited this graph to composites studied by tensile testing. In addition, in most cases, the rates of increase had to be estimated from the presented data. We assumed that polymer functionalised GO had a density similar to the matrix polymer. The theoretical maximum reinforcement is shown by the grey square. The dotted line represents ideal behaviour. B) Summery of increase in mechanical properties for graphene/polymer composites from the literature. The data consists of sets of two points joined by a line. In each case the lower data point represents the neat polymer. The upper data point represents the maximum reinforcement achieved. Note that one data set shows extremely good reinforcement. In this case the graphene volume fraction was $38 \%$ while for all other cases it was $<6 \%$. See table S1 for details of literature data. 
Figures and Schemes

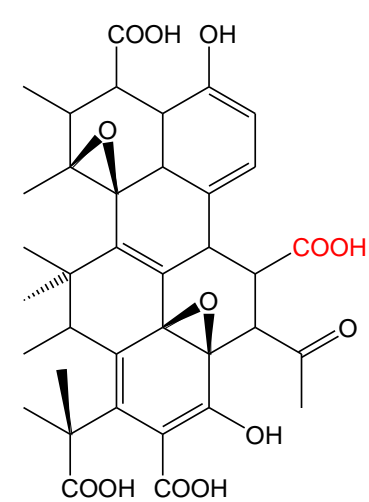

$\mathrm{R}-\mathrm{COOH}$

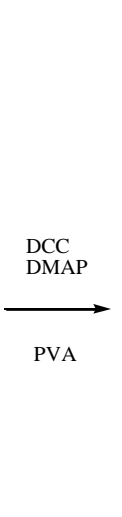

Figure 1.

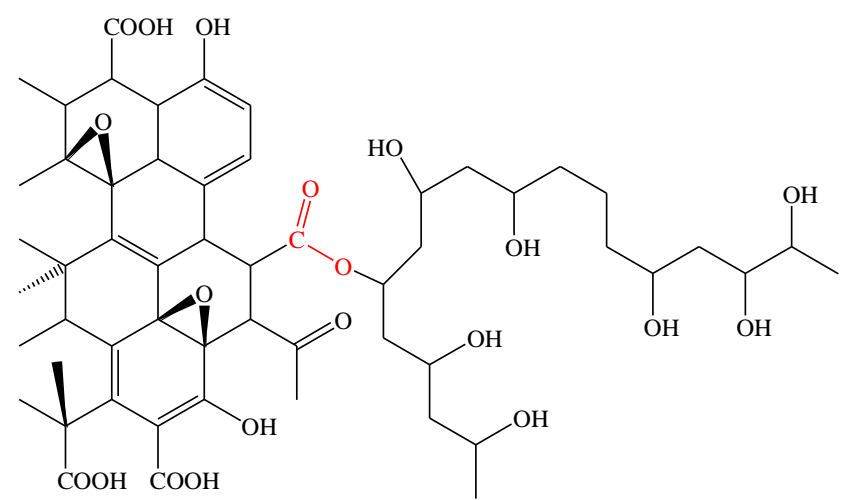

R-COO-R' 

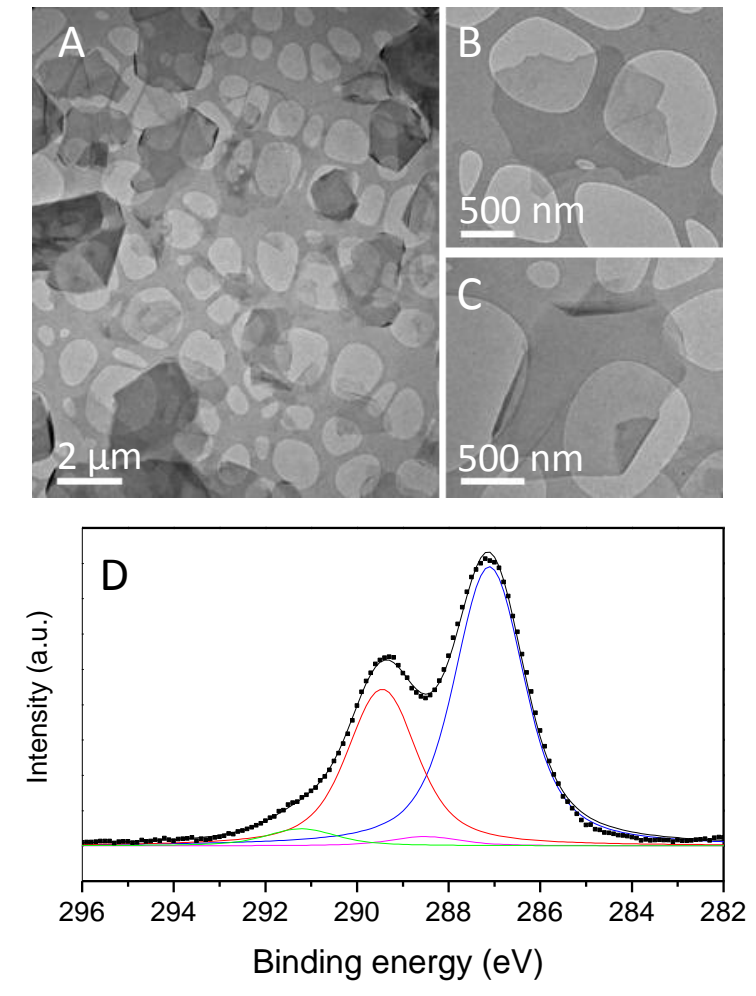

Figure 2. 


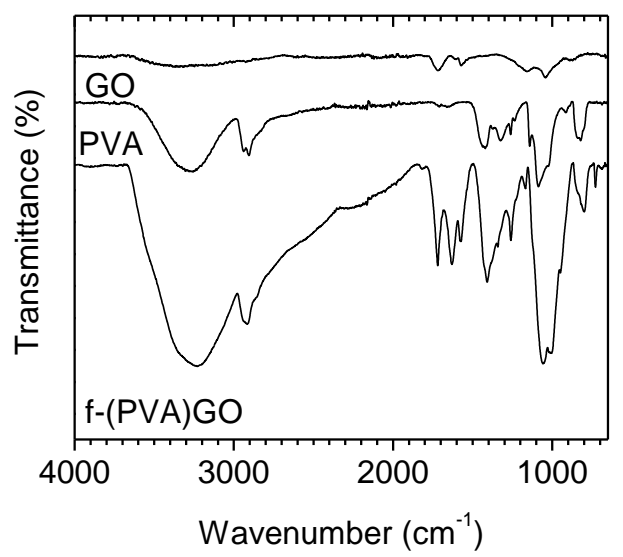

Figure 3. 

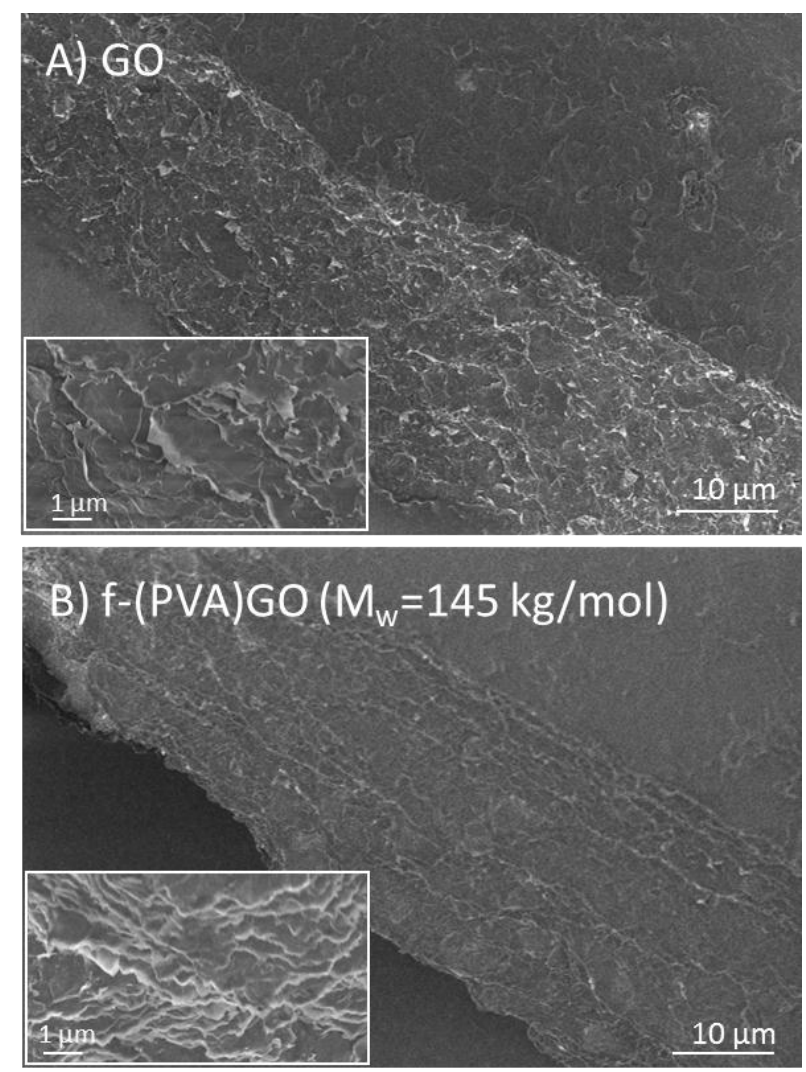

Figure 4. 

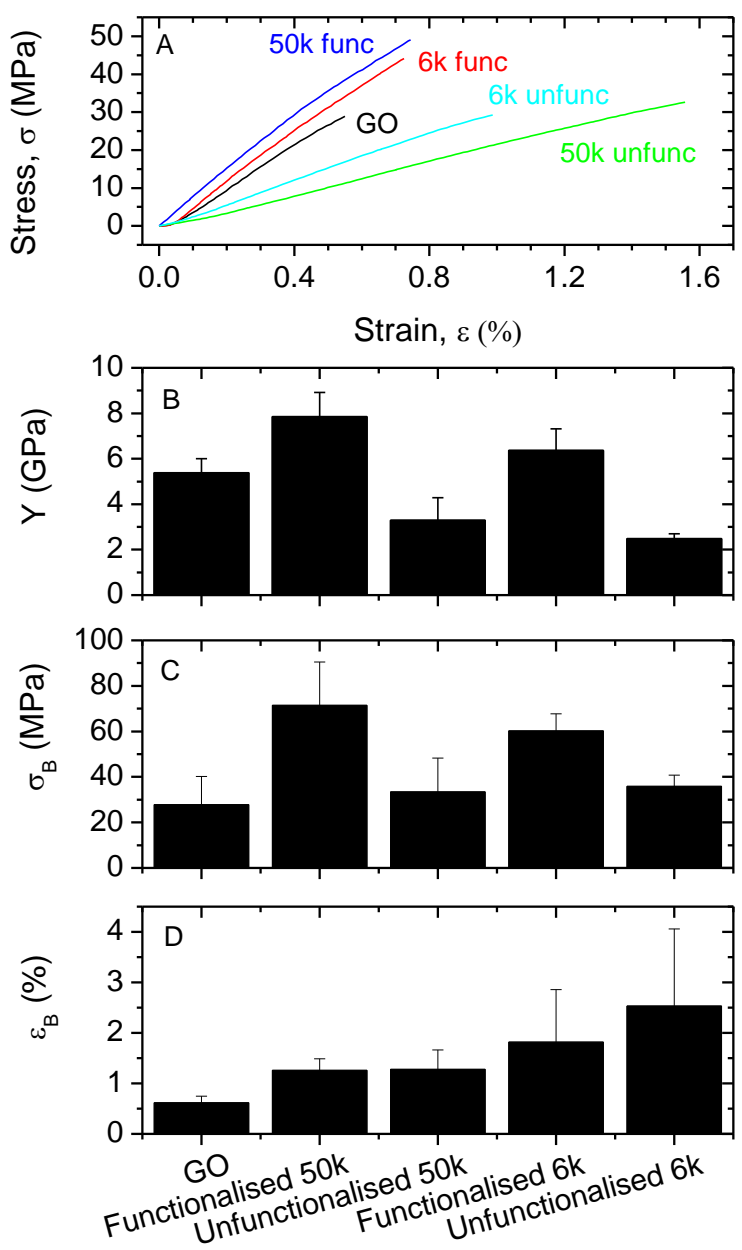

Figure 5. 


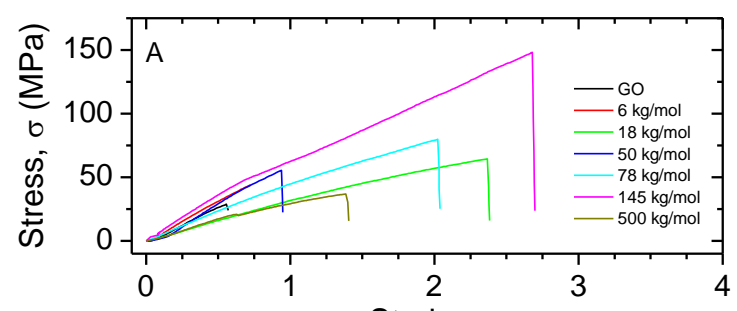

Strain, $\varepsilon$

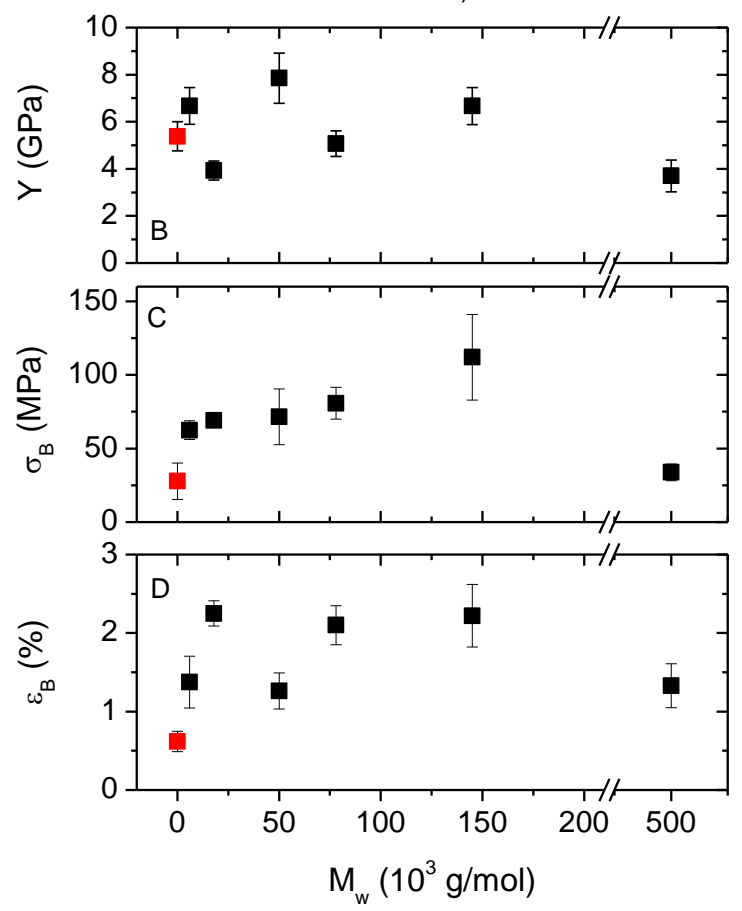

Figure 6. 

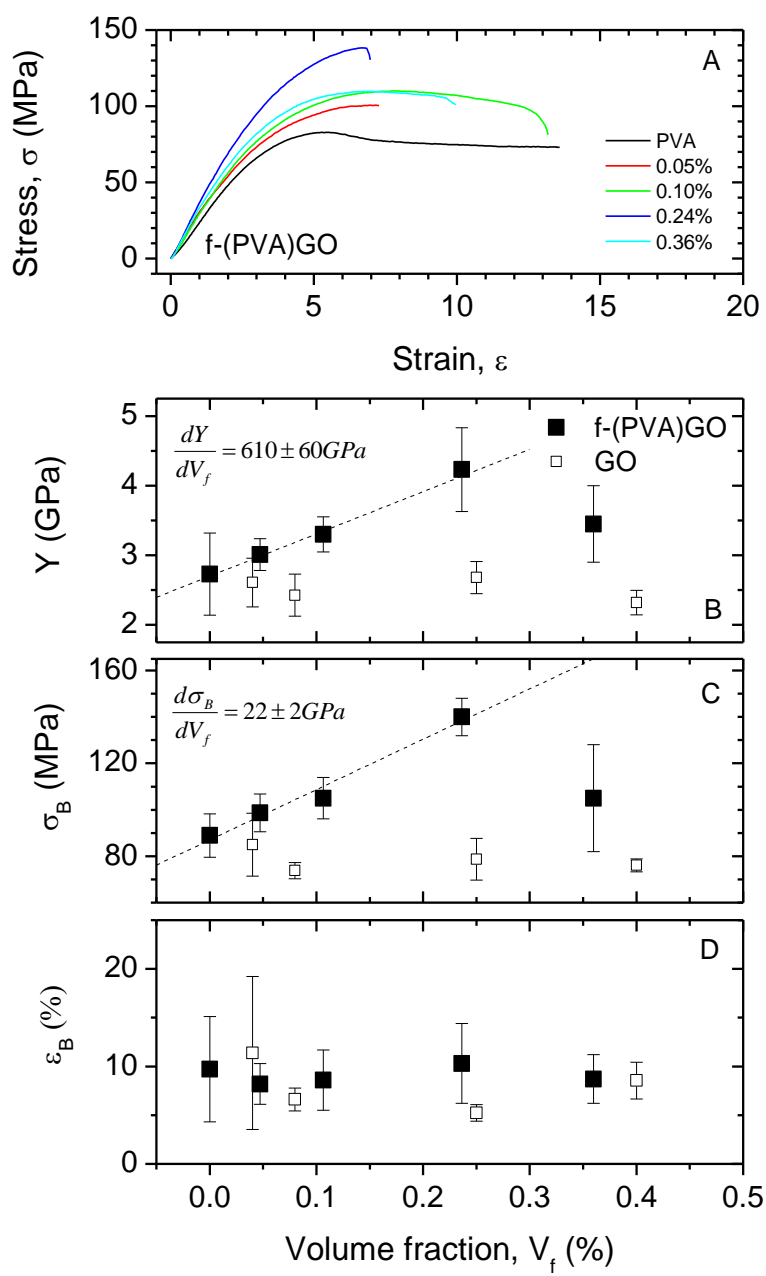

Figure 7. 

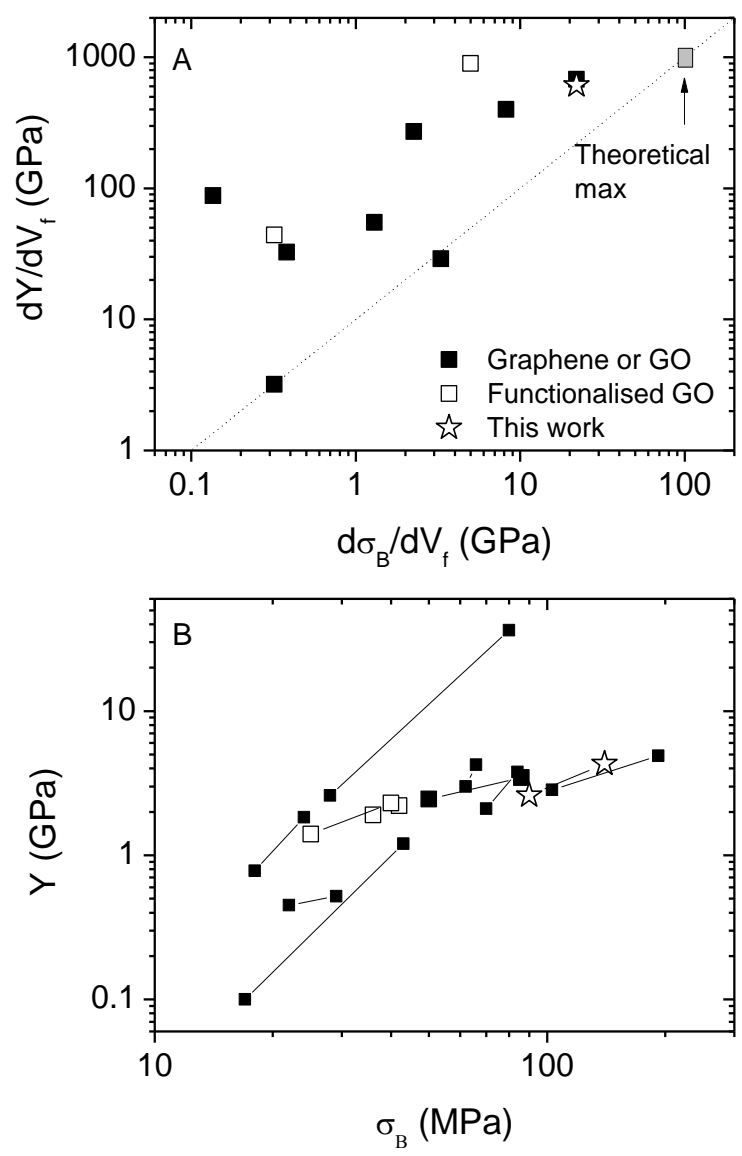

Figure 8. 


\section{RESEARCH HIGHLIGHTS}

- Graphene oxide (GO) was covalently functionalised with polyvinylalcohol (PVA)

- PVA functionalised GO, i.e. f-(PVA)GO was processed into paper-like materials

- Paper-like materials showed significant increase of mechanical properties

- Largest preselected f-(PVA)GO flakes were used as filler in PVA composites

- Composites showed significant reinforcement at filler loadings below 0.3 vol\% 
Supporting information for

Improving the Mechanical Properties of Graphene Oxide Based Materials by Covalent Attachment of Polymer Chains

Manuela Cano ${ }^{1}$, Umar Khan ${ }^{2,3}$, Toby Sainsbury ${ }^{2,3}$, Arlene O’Neill ${ }^{2,3}$, Zhiming Wang ${ }^{3}$, Ignatius McGovern $^{3}$, Wolfgang K Maser ${ }^{1}$, Ana M Benito ${ }^{1}$ and Jonathan N Coleman ${ }^{2,3}$

\begin{tabular}{|c|c|c|c|c|c|c|}
\hline Reference & Filler Material & $\begin{array}{l}\text { Polymer } \\
\text { Matrix } \\
\left(\max V_{f}\right)\end{array}$ & $\begin{array}{l}\mathrm{dY} / \mathbf{d} V_{\mathrm{f}} \\
(\mathrm{GPa})\end{array}$ & $\begin{array}{l}d \sigma_{\mathrm{B}} / \mathbf{d V} V_{\mathrm{f}} \\
(\mathrm{MPa})\end{array}$ & $\begin{array}{l}\text { Poly Y, } \\
\mathbf{Y}_{\max } \\
\text { (GPa) }\end{array}$ & $\begin{array}{l}\text { Poly } \sigma_{\mathrm{B}} \\
\sigma_{\mathrm{B} \max } \\
(\mathrm{MPa})\end{array}$ \\
\hline \multicolumn{7}{|l|}{ Graphene or GO } \\
\hline $\begin{array}{l}\text { Macromolecules, } \\
2010,43,2357\end{array}$ & RGO & $\begin{array}{l}\text { PVA } \\
(0.02)\end{array}$ & 55 & 1300 & $\begin{array}{l}0.1 \\
1.2\end{array}$ & $\begin{array}{l}17 \\
43\end{array}$ \\
\hline $\begin{array}{l}\text { Nature } \\
\text { Nanotechnology, } \\
2008,3,327\end{array}$ & $\begin{array}{l}\text { Functionalized } \\
\text { Graphene Sheets } \\
\text { (FGS) }\end{array}$ & $\begin{array}{l}\text { PMMA } \\
(0.0062)\end{array}$ & 271 & 2258 & $\begin{array}{l}2.1 \\
3.8\end{array}$ & $\begin{array}{l}70 \\
84\end{array}$ \\
\hline $\begin{array}{l}\text { Advanced } \\
\text { Functional } \\
\text { Materials, } \\
2009,19,2297\end{array}$ & GO & $\begin{array}{l}\text { PVA } \\
(0.0025)\end{array}$ & 400 & 8180 & $\begin{array}{l}2.45 \\
3.45\end{array}$ & $\begin{array}{l}50 \\
86\end{array}$ \\
\hline $\begin{array}{l}\text { Advanced } \\
\text { Functional } \\
\text { Materials, } \\
\text { 2010, 20, } 3322\end{array}$ & GO & $\begin{array}{l}\text { PVA } \\
(0.383) \\
\text { PMMA } \\
(0.65)\end{array}$ & 11 & $\begin{array}{l}136 \\
209\end{array}$ & $\begin{array}{l}2.6 \\
36.4 \\
0.67 \\
7.5\end{array}$ & $\begin{array}{l}28 \\
80 \\
12.2 \\
148\end{array}$ \\
\hline $\begin{array}{l}\text { Journal of Applied } \\
\text { Polymer Science, } \\
2010,118,275\end{array}$ & RGO & $\begin{array}{l}\text { PVA } \\
(0.003)\end{array}$ & NA & 8833 & NA & $\begin{array}{l}23 \\
49.5\end{array}$ \\
\hline $\begin{array}{l}\text { Polymer, } \\
2010, \mathbf{5 1}, 3431\end{array}$ & RGO & $\begin{array}{l}\text { PVA } \\
(0.022)\end{array}$ & 3.2 & 318 & $\begin{array}{l}0.45 \\
0.52\end{array}$ & $\begin{array}{l}22 \\
29\end{array}$ \\
\hline $\begin{array}{l}\text { Composites Science } \\
\text { and Technology, } \\
2010, \mathbf{7 0}, 1120\end{array}$ & $\begin{array}{l}\text { Expanded } \\
\text { Graphite (EG) }\end{array}$ & $\begin{array}{l}\text { Epoxy } \\
(0.016)\end{array}$ & 22 & 381 & $\begin{array}{l}0.78 \\
1.83\end{array}$ & $\begin{array}{l}17.7 \\
23.8\end{array}$ \\
\hline
\end{tabular}




\begin{tabular}{|c|c|c|c|c|c|c|}
\hline $\begin{array}{l}\text { Journal of Polymer } \\
\text { Science B, 2010, 48, } \\
850\end{array}$ & $\begin{array}{l}\text { Exfoliated } \\
\text { Graphite }\end{array}$ & $\begin{array}{l}\text { p-lactide } \\
(0.043)\end{array}$ & 29 & 2666 & $\begin{array}{l}3.0 \\
4.25\end{array}$ & $\begin{array}{l}62 \\
70\end{array}$ \\
\hline $\begin{array}{l}\text { Macromolecular } \\
\text { Rapid } \\
\text { Communications, } \\
\text { 2009, 30, } 316\end{array}$ & GO & $\begin{array}{l}\mathrm{PC} \\
(0.06)\end{array}$ & 5.3 & NA & $\begin{array}{l}2.35 \\
2.67\end{array}$ & NA \\
\hline $\begin{array}{l}\text { J. Mater. Chem } \\
2012,22,1278\end{array}$ & Pristine graphene & $\begin{array}{l}\text { PVA } \\
(0.004)\end{array}$ & 680 & 22000 & $\begin{array}{l}3 \\
4.7\end{array}$ & $\begin{array}{l}100 \\
190\end{array}$ \\
\hline \multicolumn{7}{|c|}{ Polymer-functionalised graphene } \\
\hline $\begin{array}{l}\text { J. Mater. Chem. } \\
\text { 2010, 20, } 9927\end{array}$ & GO-PMMA & $\begin{array}{l}\text { PMMA } \\
(0.01)\end{array}$ & 44 & 320 & $\begin{array}{l}1.9 \\
2.2\end{array}$ & $\begin{array}{l}36 \\
42\end{array}$ \\
\hline $\begin{array}{l}\text { J. Mater. Chem. } \\
\text { 2009, 19, } 7098\end{array}$ & GO-PS & $\begin{array}{l}\text { PS } \\
(0.009)\end{array}$ & 900 & 5000 & $\begin{array}{l}1.4 \\
2.3\end{array}$ & $\begin{array}{l}25 \\
40\end{array}$ \\
\hline $\begin{array}{l}\text { Journal of Polymer } \\
\text { Science A, } \\
2010,48,4262\end{array}$ & GO-PMMA & PMMA & 400 & & $\begin{array}{l}1.3 \\
2.0\end{array}$ & \\
\hline $\begin{array}{l}\text { J. Mater. Chem. } \\
2011,21,8612\end{array}$ & GO-PET & $\begin{array}{l}\text { PET } \\
(0.0005)\end{array}$ & & 53000 & & $\begin{array}{l}37 \\
63\end{array}$ \\
\hline
\end{tabular}

